\title{
Effects of Spheroidized Microstructure on Bainite Nucleation in SAE 52100 Steel
}

\author{
HongBo Yang ${ }^{1,2, a,}$, PeiWen Yao ${ }^{1, b}$, Lei Yang ${ }^{1,2, c}$ and MingZeng Shao ${ }^{1, d}$ \\ ${ }^{1}$ School of Metallurgical Engineering, Xi'an University of Architecture and Technology, Xi'an 710055, \\ China \\ ${ }^{2}$ Research Centre of wear-resistant material Engineering \& Technology of Shaanxi Province, Xi’an 710055, \\ China

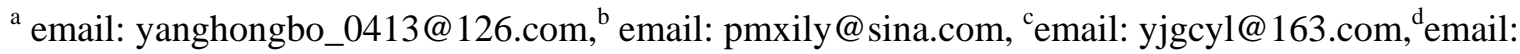 \\ smz516@163.com \\ *corresponding author: HongBo Yang
}

Keywords: 52100 steel, bainite ferrite, nucleation, cementite unit volume density, kinetics

\begin{abstract}
Annealed SAE 52100 steel samples with different spheroidized microstructures were austempered to produce a bainitic+martensitic duplex microstructure. The effects of the spheroidized microstructure on bainite ferrite (BF) nucleation during austempering were discussed. Results show that the proportion of lower bainite increased, and the BF plates initially widened and subsequently narrowed in the duplex microstructure with an increase in the unit volume density of the cementite particles $\left(\rho_{v}\right)$ in the spheroidized microstructure. An improved model was suggested to predict the bainite transformation including consummated $\alpha^{b}$ by considering the effects of $\rho_{v}$ on BF nucleation. The model was validated with the experimental data of SAE 52100 steel.
\end{abstract}

\section{Introduction}

SAE 52100 steel is the most widely used material for ball and roller applications. Some studies have demonstrated that 52100 steel with a certain amount of lower bainite is superior to that produced in a single-martensite condition in terms of mechanical properties ${ }^{[1-3]}$. The current studies on lower bainite transformation in 52100 steel primarily focus on microstructure and kinetics ${ }^{\text {[4-8] }}$.

J. Chakraborty and D. Bhattacharjee [9] determined the optimum parameters for developing a bainitic+martensitic microstructure in SAE 52100 steel. They also improved the mechanical properties of interest by controlling the ratio of lower bainite to martensite at an appropriate level. H.K.D.H. Bhadeshia and Caballero F $\mathrm{G}^{[10-11]}$ asserted that thinning bainite ferrite (BF) plates can further improve the properties of steel. Subsequently, J. Chakraborty ${ }^{[12-13]}$ obtained ultrafine bainite and martensite by prior deformation and thermomechanical processing before the austenitization or austempering of SAE 52100 steel. However, the aforementioned studies exhibited that the ratio of lower bainite to martensite can be controlled only by optimizing the process parameter of austempering. Furthermore, the effects of spheroidized cementite particles on the nucleation and growth of BF have not yet been explained. Therefore, the present study attempts to clarify the mechanisms of the nucleation and growth of BF in SAE 52100 steel during austempering (isothermal holding above the martensite start). The investigated samples are annealed at different times and then austempered under the same routine.

Theoretically, two kinetic mechanisms for bainite transformation have been proposed, namely, the diffusional mechanism ${ }^{[14]}$ and the displacive mechanism ${ }^{[15]}$. In a recent study, Van Bohemen ${ }^{[16]}$ et al. presented a model that performed reasonably well with low-silicon steels. In their displacive model, Van Bohemen et al. optimized two parameters, i.e., a temperature-dependent rate constant $(\kappa)$ and an autocatalytic factor $(\lambda)$. In this investigation, a modified model based on the displacive model of Van Bohemen et al. ${ }^{[16]}$ is suggested to predict the bainite transformation in SAE 52100 steel. The silicon content in SAE 52100 steel is similar to that in the model of Van Bohemen et al. 
The current model includes the unit volume density of cementite particles $\left(\rho_{v}\right)$, which is the number of cementite particles per unit volume in the annealed microstructure, with the effects of $\rho_{v}$ on BF nucleation considered. The model has been validated using the experimental data of SAE 52100 steel.

\section{Experimental Procedure}

\subsection{Materials}

Cylindrical samples $10 \mathrm{~mm}$ in diameter and $10 \mathrm{~mm}$ in length were cut from hot-rolled SAE 52100 steel with the following nominal composition (wt.\%): of $1.0 \mathrm{C}, 1.46 \mathrm{Cr}, 0.31 \mathrm{Mn}, 0.24 \mathrm{Si}$, $0.08 \mathrm{Cu}, 0.04 \mathrm{Ni}, 0.01 \mathrm{Mo}, 0.007 \mathrm{P}, 0.005 \mathrm{~S}$, and balance Fe.

\subsection{Procedure}

First, the samples were heated to $800{ }^{\circ} \mathrm{C}$ and held at $800{ }^{\circ} \mathrm{C}$ for $60 \mathrm{~min}$. They were then transferred to another furnace and annealed at $710{ }^{\circ} \mathrm{C}$ for different times to achieve different spheroidized microstructures. Two samples were respectively taken out after 5, 30, 90, and 150 min and subsequently air cooled to room temperature. A group of samples annealed for 5, 30, 90, and 150 min were austenitized at $900{ }^{\circ} \mathrm{C}$ for $30 \mathrm{~min}$ in air and then immediately austempered at $240{ }^{\circ} \mathrm{C}$ in a salt bath for 30 min to produce the bainitic+martensitic duplex microstructure. Finally, the samples were quenched in a water bath at room temperature.

All samples were mechanically polished with diamond paste (up to $0.1 \mu \mathrm{m}$. The annealed samples were etched with $4 \%$ nital solution, and the austempered samples were etched with LePera's solution. The detailed microstructures in the center of the polished and etched samples were observed using an optical microscope (with an image analyzer) and a field-emission scanning electron microscope (FESEM). Moreover, the $\rho_{v}$ in the annealed microstructure, the volume fraction $(f)$, and the average width of the BF plate in the bainitic+ martensitic duplex microstructure were calculated based on the average value of 10 randomly selected fields.

\section{Results and Discussions}

\subsection{Microstructure}

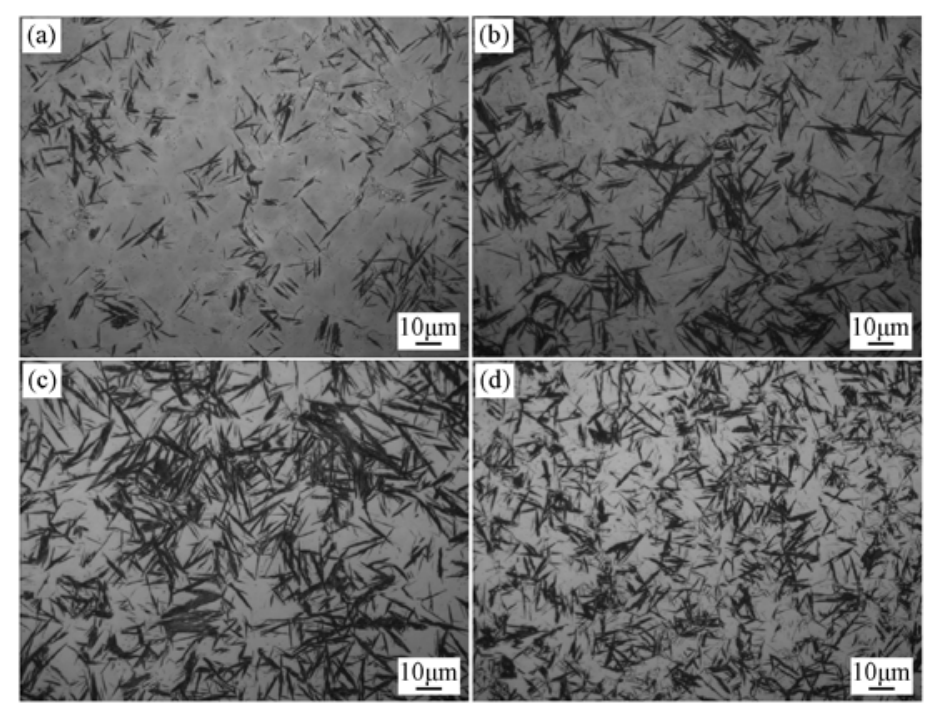

Fig.1 Optical microstructure of SAE52100 steel austempered at $240^{\circ} \mathrm{C}$ for $30 \mathrm{~min}$ after annealing. The samples were annealed at $710^{\circ} \mathrm{C}$ for (a) $5 \mathrm{~min}$, (b)30 min, (c)90min, and(d)150min, respectively.

Figure 1 presents the optical microstructure of the samples subjected to the same austempering treatment after different annealing schedules, and Figure 2 shows the FESEM microstructure of lower bainite. As shown in these figures, the volume fraction of lower bainite gradually increases with an increase in annealing time. The BF plate widens with an increase in annealing time, when 
annealing time is less than 90 min. The BF plate width in the sample annealed for 90 min is approximately $6.05 \mu \mathrm{m}$ (Figure 3). Nevertheless, the BF plate has obviously narrowed to $1.19 \mu \mathrm{m}$ after 150 min annealing (Figure 3).

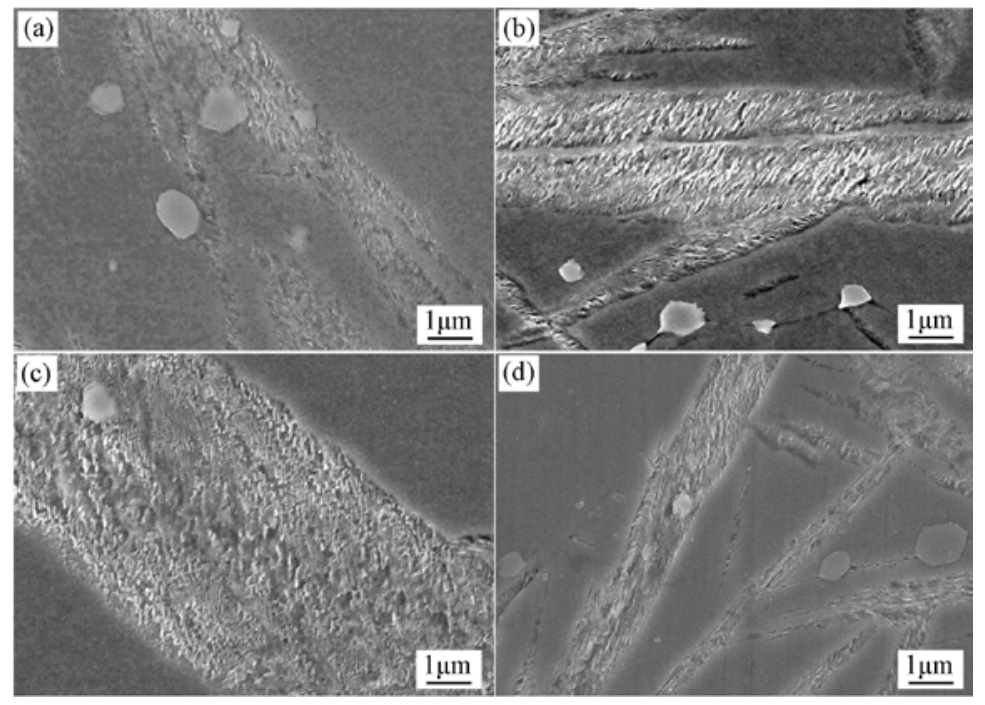

Fig.2 FESEM microstructure of SAE52100 steel austempered at $240^{\circ} \mathrm{Cafter}$ annealing for (a)5min, (b)30min, (c) $90 \mathrm{~min}$, and(d)150min, respectively.

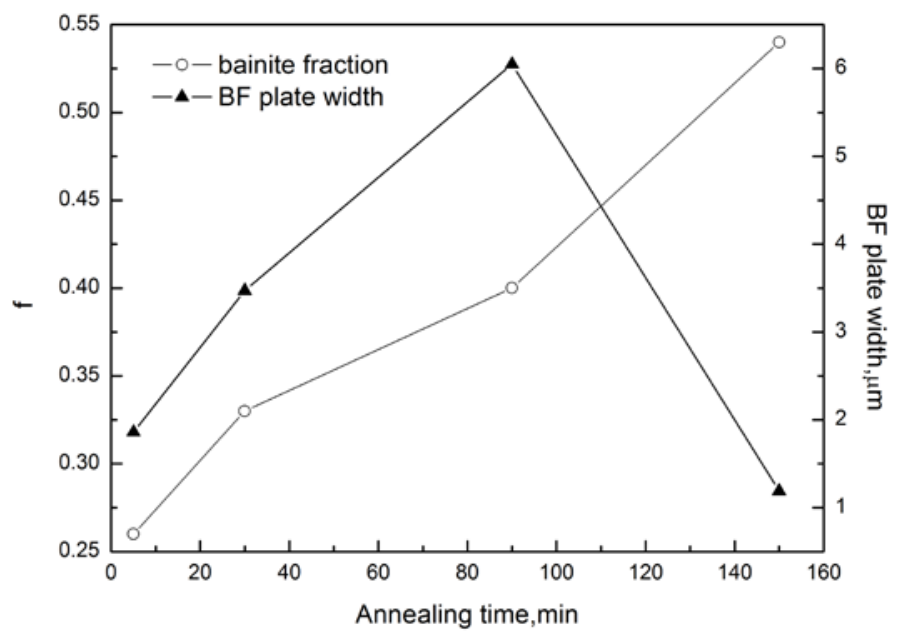

Fig.3 Volume fraction of lower bainite and BF plate width vs. annealing time.

Bainite transformation is assumed to start with the nucleation of BF sub-units because of preexisting defects ${ }^{[17]}$. Subsequently, autocatalytic nucleation occurs at the tips of the sub-units. By the repetition of this process, the familiar plate structure of bainite develops. Therefore, the pre-existing defects are of importance to the nucleation of BF. Calculated according to the micrograph of SAE 52100 steel annealed at $710{ }^{\circ} \mathrm{C}$ for different times, the $\rho_{v}$ in the annealed samples is shown in Figure 4. As shown in Figure 4, $\rho_{v}$ increases with an increase in annealing time. The more the cementite particles in the spheroidized microstructure are, the more dispersed the undissolved cementite particles are during re-austenitization, the more the pre-existing defects are, and the more BF nucleation sites are during austempering. Thus, a new sub-unit of BF forms continuously on the side of the old one. Subsequently, the length and width of the BF plate gradually increase, and the volume fraction of lower bainite also increases in the process of lower bainite transformation when the sample is annealed for less than $90 \mathrm{~min}$. 


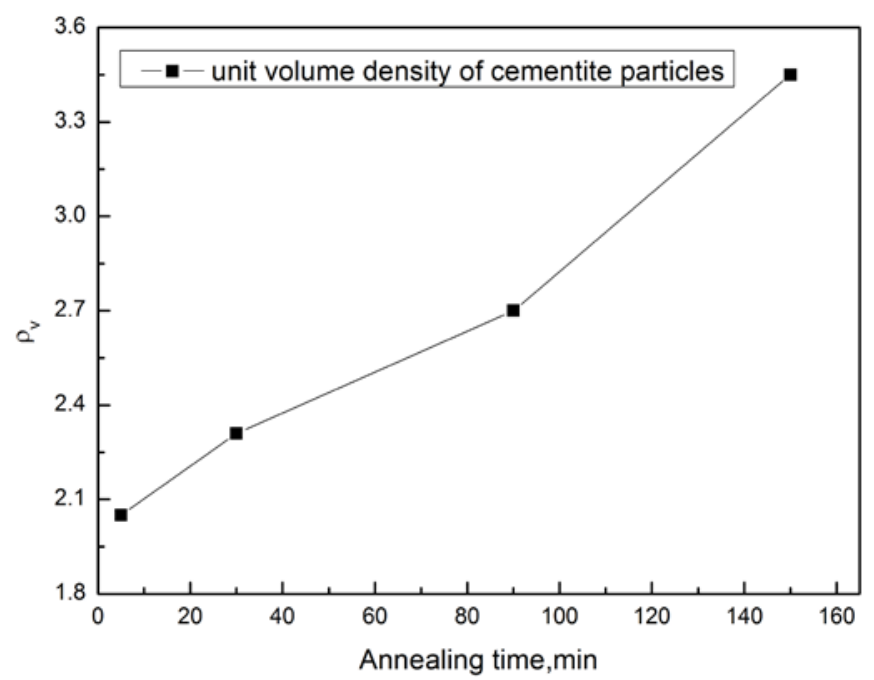

Fig.4 Unit volume density of cementite particle vs. annealing time in the annealed SAE 52100 steel.

The quality volume of ferrite with a body-centered cubic lattice is larger. Distortion stress and distortion energy appear because of the volume expansion during BF transformation. The BF plate stops growing when the distortion energy is sufficiently large. Moreover, the distortion energy can stimulate nucleation. When the annealing time is $90-150 \mathrm{~min}, \rho_{v}$ increases from 2.7 to 3.45 , as shown in Figure 4. A large quantity of undissolved cementite particles are retained during reaustenitization when $\rho_{v}$ is 3.45. The undissolved particles hinder the BF plate from growing during austempering, and the distortion energy consequently increases. The increased distortion energy stimulates the new BF nucleus to generate in the process of lower bainite transformation. Therefore, although the volume fraction of lower bainite increases continuously, the width of the BF plate obviously decreases after 150 min annealing.

\subsection{Model}

In the displacive model, the individual sub-units are considered to grow at considerably rapid rates. Therefore, a thorough understanding of the nucleation in displacive transformation is highly important, because it is the key factor in controlling the overall transformation kinetics. According to Van Bohemen et al. ${ }^{[16]}$, the rate of change in the volume fraction of bainite can be expressed as:

$$
\frac{d f}{d t}=\frac{d N}{d t} V_{b}
$$

Where $f$ is the volume fraction of bainite, $N$ is the number of nucleation sites, and $V_{b}$ is the average volume of the bainite subunits. The rate of bainite nucleation in a sample at a temperature $T$ according to Ref. ${ }^{[16]}$ is expressed as:

$$
\frac{d N}{d t}=\frac{k T}{h}(1-f) N_{i}(1+\lambda f) \exp \left(-\frac{Q^{*}}{k T}\right)
$$

Where $k$ is the Boltzmann constant, $T$ is the temperature in Kelvin, $h$ is the Planck's constant, $\lambda$ is the autocatalytic nucleation parameter, $Q^{*}$ is the activation energy. $N_{i}$ is the number density of the potential nucleation sites that are initially present in the austenite, the so-called pre-existing defects, is given in Ref. ${ }^{[16]}$ as:

$$
N_{i}=\frac{\alpha}{V_{b}}\left(T_{h}-T\right)
$$

The temperature $T_{h}$ used for normalization represents the maximum temperature at which bainite formation takes place, and has been calculated using JMatPro with a value of $476{ }^{\circ} \mathrm{C}$ in the present model. All parameters used for the model calculation are listed in Table 1. 
Table1 Overview of parameters used for the model calculations.

\begin{tabular}{|c|c|c|c|c|c|c|c|c|}
\hline $\begin{array}{l}\mathrm{T}_{\mathrm{h}} \\
(\mathrm{k})\end{array}$ & $\begin{array}{c}\mathrm{T} \\
(\mathrm{k})\end{array}$ & $\begin{array}{c}\alpha_{\mathrm{m}} \\
\left(\mathrm{k}^{-1}\right)\end{array}$ & Z & $\begin{array}{c}\delta \\
(\mu \mathrm{m})\end{array}$ & $\begin{array}{c}\mathrm{d} \\
(\mu \mathrm{m})\end{array}$ & $\begin{array}{c}\mathrm{K} \\
\left(10^{-5} \mathrm{~s}^{-1}\right)\end{array}$ & $\begin{array}{c}\mathrm{Q}^{*} \\
\left(\mathrm{~kJ} \cdot \mathrm{mol}^{-1}\right)\end{array}$ & $\lambda$ \\
\hline 749 & 513 & 0.0245 & 0.15 & 1 & 146 & 3.35 & 160 & 52 \\
\hline
\end{tabular}

Unfortunately, $\alpha$ only is experimentally investigated for martensite formation. In the case of martensite formation $\alpha^{m}$ has a value in the range of $0.01-0.07 \mathrm{~K}^{-1}$, and depends slightly on the chemical composition ${ }^{[18]}$. In the present study, that has been obtained by linear extrapolation from the values reported by S.M.C. van Bohemen et al. ${ }^{[19]}$ (see Table 1).Based on the difference between martensite and bainite nucleation it is proposed to calculated $\alpha^{b}$ in Ref. [16] as:

$$
\alpha^{b}=\frac{z \delta}{d} \alpha^{m}
$$

With $\delta$ the effective thickness of the austenite grain boundary, $Z$ a geometrical factor and $d$ austenite grain size. The $\alpha^{b}$ is related to the pre-existing defects, which is important for the analysis of bainite nucleation with different spheroidized microstructure. It should be noted that $\alpha^{b}$ is inversely proportional to the austenite grain size (Eq. (4)), but the relation between $\alpha^{b}$ and spheroidized microstructure is poor. Therefore, that is expressed in the present model as:

$$
\alpha^{b}=\frac{\delta \rho_{v} \exp \left(-z \delta \rho_{v}\right)}{d} \alpha^{m}
$$

Where $\rho_{v}$ is the unit volume density of cementite particles in spheroidized microstructure. Based on the measured austenite grain diameters $d$, of $146 \mu \mathrm{m}, \alpha^{b}$ was calculated using Eq. (5) with $Z=0.15$, $\delta=1 \mu \mathrm{m}$, and $\alpha^{m}=0.0245 \mathrm{~K}^{-1}$. Thus,

$$
\alpha^{b}=1.68 \times 10^{-4} \rho_{v} \exp \left(-0.15 \rho_{v}\right)
$$

Integrating Eq. (1) using the Eq. (2) and (3), we obtain Van Bohemen et al.'s expression as:

$$
\begin{aligned}
\frac{d f}{d t} & =(1-f)(1+\lambda f) \kappa \\
\kappa & =\frac{k T}{h} \alpha^{b}\left(T_{h}-T\right) \exp \left(-\frac{Q^{*}}{k T}\right)
\end{aligned}
$$

In this work, the activation energy $Q^{*}$ of the austenite to bainite transformation, and specific $\lambda$ factor were from Van Bohemen et al. ${ }^{[14]}$ by a linear extrapolation, respectively, of $160 \mathrm{~kJ}$ and 52. Van Bohemen et al.’s rate parameter, $\kappa$, was replaced by the new rate parameter, $m$, where:

$$
m=1.68 \times 10^{-4} \rho_{v} \exp \left(-0.15 \rho_{v}\right) \frac{k T}{h}\left(T_{h}-T\right) \exp \left(-\frac{Q^{*}}{k T}\right)
$$

Thus, $f$ can be written as an explicit function of time as:

$$
f=\frac{1-\exp (-m(1+\lambda) t)}{\lambda \exp (-m(1+\lambda) t)+1}
$$

The calculated volume fraction of bainite using Eq. (10) was compared to the experimental datum for SAE52100 steel with different $\rho_{v}$.

\section{Conclusions}

The quantity of nucleation sites for BF during lower bainite transformation can be affected by the unit volume density of cementite particles $\left(\rho_{v}\right)$ in the spheroidized microstructure of SAE 52100 steel. The larger the $\rho_{v}$ in the spheroidized microstructure is, the more dispersed the undissolved 
cementite particles are during re-austenitization, the more pre-existing defects are, and the more the BF nucleation sites are during austempering.

Finer lower bainite can be obtained during austempering by increasing $\rho_{v}$ in the spheroidized microstructure of SAE 52100 steel. When $\rho_{v}$ ranges from 2.7 to 3.45, the width of BF plates decreases from $6.05 \mu \mathrm{m}$ to $1.19 \mu \mathrm{m}$. An improved model including consummated $\alpha^{b}$ for bainite kinetics is established in this work by considering to the effects of $\rho_{v}$ on BF nucleation. The model has been validated with the experimental data of SAE 52100 steel.

\section{Acknowledgements}

The authors would like to thank the financial support provided by the Natural Science Foundation of Shaanxi Province (No. 2016JM5060), Educational Commission of Shaanxi Province (No. 16JS053), and Open Foundation of Research Centre of wear-resistant material Engineering \& Technology of Shaanxi Province (No.2016 NMZX08).

\section{References}

[1] F.C. Akbasoglu and D.V. Edmonds: Metall.Trans. 21A (1990)889-892.

[2]H.K.D.H.Bhadeshia and C.H.Young: Mater.Sci.Technol.10 (1994)209.

[3] Meng-Yin Tu, Cheng-An Hsu and Wen-Hsiung Wang: Mater. Chem. Phys. 107(2008)418-425.

[4] Z Q Zhang, Y Z Liu and Z Q Fan: Trans. Mater. Heat Treat. 23(2002)57-60.

[5] A. Kumar, S.B. Singh and K.K. Ray: Mater. Sci. Eng. A. 474(2008)270-282.

[6] H.K.D.H. Bhadeshia: Progress in Materials Science 57(2012)268-435.

[7] G.Sidhu, S.D.Bhole, D.L.Chen and E.Essadiqi: Script Mater.64 (2011)73-76.

[8] NV.Luzginova, L.Zhao and J.Sietsma: Mater. Sci. Eng. A.481-482(2008)766-769.

[9] J. Chakraborty, D. Bhattacharjee, I. Manna: Scripta Mater. 61(2009)604-607.

[10] Caballero F G and Bhadeshia H K D H: Current Opinion in Solid State and Materials Science.8 (2004) 251-257.

[11] H.K.D.H. Bhadeshia: Materials Science Forum, 500(2005) 63-74.

[12] J. Chakraborty, D. Bhattacharjee and I. Manna: Scripta Mater. 61(2009)604-607.

[13] J. Chakraborty and I. Manna. Mat. Sci.Eng. A, 548(2012)33-42.

[14] H.I.Aaronson, G.Spanos, et al: Scr.Mater.47 (2002)139-144.

[15]M.J.Santofimia,F.G.Caballero,C.Capdevila,C.Garcia-Mateo,C.G.de Andres:Mater.Trans.47(2006)1492.

[16] Stefan M. C. van Bohemen and Jilt Sietsma: Int. J. Mat. Res.99 (2008)739-747.

[17] H.K.D.H. Bhadeshia: Bainite in steels, The Institute of Materials, London (2001).

[18] C.L. Magee: The nucleation of martensite. In: Phase Transformations: American Society of Metals, 1970, 115.

[19] S.M.C. van Bohemen, J. Sietsma, M.J.M. Hermans and I.M. Richardson. Acta Mater. 51 (2003) 4183-4196. 